\title{
Prevalence of SARS-CoV-2 in Pregnant Women Assessed by RT-PCR in Franconia, Germany: First Results of the SCENARIO Study (SARS-CoV-2 prEvalence in pregNAncy and at biRth In FrancOnia)
}

\author{
Prävalenz von SARS-CoV-2 bei schwangeren Frauen ermittelt \\ durch RT-PCR in Franken, Deutschland: erste Ergebnisse \\ der SCENARIO-Studie (SARS-CoV-2 prEvalence in pregNAncy \\ and at biRth In FrancOnia)
}

\section{()(1) (요 $\ominus$}

Authors

Alexander Hein ${ }^{1}$, Sven Kehl ${ }^{1}$, Lothar Häberle ${ }^{1}$, Carsten Tiemann ${ }^{2}$, Rebecca Peuker ${ }^{1}$, Denise Mereutanu ${ }^{1}$, Florian M. Stumpfe ${ }^{1}$, Florian Faschingbauer ${ }^{1}$, Kirstin Meyer-Schlinkmann'², Martin C. Koch ${ }^{3}$, Franz Kainer ${ }^{4}$, Ulf Dammer ${ }^{5}$, Hanna Philipp ${ }^{6}$, Carolin Kladt ${ }^{7}$, Michael G. Schrauder ${ }^{8}$, Stefan Weingärtler ${ }^{9}$, Volker Hanf ${ }^{10}$, Arndt Hartmann ${ }^{11}$, Matthias Rübner ${ }^{1}$, Holm Schneider ${ }^{12}$, Jos Lelieveld ${ }^{13}$, Matthias W. Beckmannn ${ }^{1}$, Lena A. Wurmthaler ${ }^{1}$, Peter A. Fasching ${ }^{1}$, Michael O. Schneider ${ }^{1}$

Affiliations

1 Department of Gynaecology and Obstetrics, Erlangen University Hospital, Friedrich-Alexander University

Erlangen-Nürnberg, Erlangen, Germany

2 MVZ Labor Krone GbR, Bad Salzuflen, Germany

3 Department of Gynaecology and Obstetrics, ANregiomed Klinikum Ansbach, Ansbach, Germany

4 Department of Gynaecology and Obstetrics, Klinik Hallerwiese, Nürnberg, Germany

5 Department of Gynaecology and Obstetrics, St. Theresien-Krankenhaus, Nürnberg, Germany

6 Department of Gynaecology and Obstetrics, REGIOMED Klinikum Coburg, Coburg, Germany

7 Department of Gynaecology and Obstetrics, Clinic Bayreuth, Bayreuth, Germany

8 Department of Gynaecology and Obstetrics, Klinikum Aschaffenburg-Alzenau, Aschaffenburg, Germany

9 Department of Gynaecology and Obstetrics, Klinikum Forchheim-Fränkische Schweiz, Forchheim, Germany

10 Department of Gynaecology and Obstetrics, Klinikum Fürth, Fürth, Germany

11 Institute of Pathology, Erlangen University Hospital, Friedrich-Alexander University Erlangen-Nürnberg, Erlangen, Germany

12 Department of Pediatrics, Erlangen University Hospital, Friedrich-Alexander University Erlangen-Nürnberg, Erlangen, Germany

13 Max-Planck Institut für Chemie, Mainz, Germany
Key words

SARS-CoV-2, COVID-19, pregnancy, prevalence, infection

Schlüsselwörter

SARS-CoV-2, COVID-19, Schwangerschaft, Prävalenz,

Infektion

received

11.11. 2021

accepted after revision

22. 12.2021

Bibliography

Geburtsh Frauenheilk 2022; 82: 226-234

DOI $\quad 10.1055 / a-1727-9672$

ISSN 0016-5751

(c) 2022. The Author(s).

This is an open access article published by Thieme under the terms of the Creative Commons Attribution-NonDerivative-NonCommercial-License, permitting copying and reproduction so long as the original work is given appropriate credit. Contents may not be used for commercial purposes, or adapted, remixed, transformed or built upon. (https://creativecommons.org/licenses/by-nc-nd/4.0/)

Georg Thieme Verlag KG, Rüdigerstraße 14,

70469 Stuttgart, Germany

Correspondence

PD Dr. med. Alexander Hein

Erlangen University Hospital, Friedrich-Alexander University

Erlangen-Nürnberg, Department of Gynaecology and Obstetrics

Universitätsstraße 21-23, 91054 Erlangen, Germany

alexander.hein@uk-erlangen.de

Supplementary material is available under

https://doi.org/10.1055/a-1727-9672 


\section{ABSTRACT}

Purpose Detection of SARS-CoV-2-infected pregnant women admitted to maternity units during a pandemic is crucial. In addition to the fact that pregnancy is a risk factor for severe COVID-19 and that medical surveillance has to be adjusted in infected women and their offspring, knowledge about infection status can provide the opportunity to protect other patients and healthcare workers against virus transmission. The aim of this prospective observational study was to determine the prevalence of SARS-CoV-2 infection among pregnant women in the hospital setting.

Material and Methods All eligible pregnant women admitted to the nine participating hospitals in Franconia, Germany, from 2 June 2020 to 24 January 2021 were included. COVID-19-related symptoms, secondary diseases and pregnancy abnormalities were documented. SARS-CoV-2 RNA was detected by RT-PCR from nasopharyngeal swabs. The prevalence of acute SARS-CoV-2 infection was estimated by correcting the positive rate using the Rogan-Gladen method. The risk of infection for healthcare workers during delivery was estimated using a risk calculator.

Results Of 2414 recruited pregnant women, six were newly diagnosed RT-PCR positive for SARS-CoV-2, which yielded a prevalence of SARS-CoV-2 infection of $0.26 \%$ (95\% Cl, 0.10 $0.57 \%$ ). Combining active room ventilation and wearing FFP2 masks showed an estimated reduction of risk of infection for healthcare workers in the delivery room to $<1 \%$.

Conclusions The prevalence of newly diagnosed SARS-CoV-2 infection during pregnancy in this study is low. Nevertheless, a systematic screening in maternity units during pandemic situations is important to adjust hygienic and medical management. An adequate hygienic setting can minimise the calculated infection risk for medical healthcare workers during patients' labour.

\section{ZUSAMMENFASSUNG}

Zielsetzung Das Erkennen von SARS-CoV-2-Infektionen bei schwangeren Frauen, die während der Pandemie in eine geburtshilfliche Abteilung aufgenommen werden, ist essenziell. Bekanntlich stellt die Schwangerschaft einen Risikofaktor für die Entwicklung einer schweren COVID-19-Erkrankung dar, und die medizinische Überwachung von infizierten Frauen und ihren Kindern muss dementsprechend angepassst werden. Das Wissen um den Infektionsstatus von Patientinnen macht es möglich, andere Patientinnen und das medizinische Fachpersonal vor einer Übertragung des Virus zu schützen. Ziel dieser prospektiven Beobachungsstudie war es, die Prävalenz von SARS-CoV-2-Infektionen bei schwangeren Frauen im Krankenhaus zu bestimmen.

Material und Methoden Alle schwangeren Frauen, die in einem der 9 teilnehmenden Krankenhäuser in Franken, Deutschland, zwischen dem 2. Juni 2020 und dem 24. Januar 2021 vorstellig waren, wurden in die Studie aufgenommen. COVID-19-bedingte Symptome, sekundäre Erkrankungen und Schwangerschaftsanomalien wurden dokumentiert. Die mit nasopharyngealen Abstrichen entnommene SARSCoV-2-RNA wurde mittels RT-PCR detektiert. Ausgehend von der Rate positiver Fälle wurde die wahre Prävalenz von akuten SARS-CoV-2-Infektionen mit der Rogan-Gladen-Methode geschätzt. Das Infektionsrisiko für das medizinische Fachpersonal während der Entbindung wurde unter Zuhilfenahme eines Risikoberechners geschätzt.

Ergebnisse Bei 6 von insgesamt 2414 in die Studie rekrutierten schwangeren Frauen wurde nach einer RT-PCR-Diagnostik eine SARS-CoV-2-Infektion erstdiagnostiziert. Das entspricht einer Prävalenz von SARS-CoV-2-Infektionen von 0,26\% (95\%-KI 0,10-0,57\%). Eine aktive Raumbelüftung in Kombination mit dem Tragen von FFP2-Masken verringerte das geschätzte Risiko einer Infektion für das im Entbindungssaal tätige medizinische Fachpersonal auf $<1 \%$.

Schlussfolgerungen Die Prävalenz einer neuen SARS-CoV-2Infektion während der Schwangerschaft war in dieser Studie gering. Trotzdem ist es wichtig, während der Pandemie systematische Untersuchungen in geburtshilflichen Abteilungen durchzuführen, um die Hygienemaßnahmen und die medizinische Betreuung im Falle einer Infektion anzupassen. Angemessene Infektionsschutzmaßnahmen können das kalkulierte Risiko für das medizinische Fachpersonal während der Geburtsbetreuung minimieren.

\section{Introduction}

SARS-CoV-2 (severe acute respiratory syndrome coronavirus 2) was isolated for the first time in January 2020. The disease resulting from this highly contagious coronavirus, which is transmitted from person to person and spread into a pandemic within a few months, is called COVID-19 (coronavirus disease 2019) [1-3]. Information about impact of SARS-CoV-2 infection on pregnant women and their offspring was limited in the first months of the pandemic [4], but increased exponentially. Currently, there is no evidence of greater susceptibility to SARS-CoV-2 in pregnancy [2, $5,6]$; however, detecting infection in pregnant women is important for several reasons.
Infected pregnant women are at higher risk of severe COVID19 symptoms compared to non-pregnant women and therefore need close medical surveillance. About one third of pregnant women with COVID-19 are hospitalised compared to $6 \%$ of nonpregnant women $[7,8]$. The risk of admission to intensive care in pregnant women with COVID-19 (3-31\%) is greater than in nonpregnant women with COVID-19 (relative risk, RR, 3.0; confidence interval [Cl] 2.6-3.4) [9-17]. The risk of needing invasive ventilation is reported to be $1.3-14 \%$ (RR 2.9, compared to non-pregnant women, $95 \% \mathrm{Cl} 2.2-3.8)[7,11,14,15,17]$. The mortality rate of pregnant women with COVID-19 also seems to be greater than that of their non-pregnant peers with COVID-19 (RR 1.7, $95 \% \mathrm{Cl} 1.2-2.4$ ) [8], as well as that of pregnant women without 
COVID-19 (OR 2.85, 95\% Cl 1.08-7.52) [17], and currently ranges from $0.1-1.5 \%[7,8,15]$.

Another concern regarding infected pregnant women is the possible transmission to the unborn child. Although intrauterine vertical transmission is possible [18-23], most babies are infected peri- and postnatally from mothers with SARS-CoV-2 infection in late pregnancy (4\%) [24-26]. Early neonatal infection is generally mild, but the long-term effects of early-life exposure to SARS-CoV-2 are unknown [27]. Detecting infected mothers and screening their offspring for perinatal transmission could help us understand the short- and long-term consequences of neonatal infection.

Finally, knowledge about the infection status of pregnant women admitted to hospital during a pandemic is crucial in order to protect other patients and health care workers against viral transmission. Considering the high proportion of asymptomatic infections (up to $79-88 \%[28,29]$ ), universal screening is an important tool to avoid nosocomial SARS-CoV-2 infection [30,31].

The primary aim of this prospective observational study was to determine the prevalence of acute SARS-CoV-2 infection in pregnant women admitted to hospitals in Franconia, Germany.

\section{Material and Methods}

\section{Study design}

The SCENARIO study (SARS-CoV-2 prEvalence in pregNAncy and at biRth In FrancOnia), a prospective observational study, included all the pregnant women at nine clinical centres in Franconia. The region of Franconia is situated in south Germany, consists of 4.16 million residents [32] and had 38856 live births in 2020 [33].

This first evaluation of the SCENARIO study focuses on the prevalence of acute SARS-CoV-2 infection in pregnant women admitted to participating hospitals in Franconia, Germany. Recruitment of pregnant women for this analysis began on 2 June 2020 and ended on 24 January 2021.

The study was approved by the ethics committee at the medical faculty of the Friedrich-Alexander-Universität Erlangen-Nürnberg, Germany (185_20 B).

\section{Patient sampling and clinical information}

All pregnant women who presented to the participating clinics as inpatients or outpatients, regardless of whether it was an emergency visit or a planned visit, were screened for the inclusion in the study. After giving informed written consent, anamnestic evidence of COVID-19-related symptoms was collected and documented. Secondary diseases and abnormalities during pregnancy were self-reported by the participants in a questionnaire (see Supplement) at the baseline visit. The gestational age was determined on the basis of the last menstrual period and, if necessary, corrected on the basis of the crown-rump length.

\section{Reverse-transcription polymerase chain reaction and serological testing}

Each participating woman underwent a nasopharyngeal swab to detect SARS-CoV-2 ribonucleic acid (RNA). Direct detection of the pathogen was carried out in accordance with the recommendations of the Robert Koch Institute (RKI) and the World Health Organization (WHO) via RNA detection using real-time reversetranscription polymerase chain reaction (RT-PCR) [34]. The tests were performed in the clinic's own laboratories or in a central laboratory, depending on local availability. All testing laboratories were accredited and RT-PCR tests were performed according to the manufacturers' standardised protocols.

\section{Statistical Analysis}

The study's primary aim was to assess the prevalence of acute SARS-CoV-2 infection in pregnant women. The positive test rate obtained from the RT-PCR measurements was determined, and its $95 \% \mathrm{Cl}$ was calculated using the Clopper-Pearson method. In accordance with other studies in the context of COVID-19 research [35], the positive test rate was defined as the number of people who tested positive divided by the number of the reference population, without considering person-time.

The prevalence of SARS-CoV-2 infection was estimated by correcting the positive test rate for possible misclassification bias using the Rogan and Gladen's method [36] with sensitivity and specificity values according to Corman et al. [37]. A 95\% Cl for the prevalence was calculated by applying the Rogan-Gladen method to the lower and the upper bound of the $95 \% \mathrm{Cl}$ for the positive test rate.

Participants with a missing RT-PCR test result were excluded from analyses. Participants with known prior detection of SARSCoV-2 before study entry were also excluded from analyses.

Calculations were carried out using the R system for statistical computing (version 3.6.1; R Development Core Team, Vienna, Austria, 2019).

\section{Estimation of infection risk with SARS-CoV-2 for health care workers}

As there was a significant total number of infectious patients in the study, we estimated the risk of infection with SARS-CoV-2 for midwives and obstetricians in delivery settings, using a risk calculator for COVID-19 aerosol transmission and infection risk in indoor environments (Max Planck Institute for Chemistry, Germany) [38]. This tool which is available online (https://www.mpic.de/ $4747361 /$ risk-calculator) is based on an adjustable algorithm to estimate the infection risk for different indoor environments, constrained by published data of human aerosol emissions, SARSCoV-2 viral loads, infective dose and other parameters. Risk was calculated for a common labour in a delivery room with different scenarios - for both, average and highly infectious mothers, and with different ventilation and mask-settings. The parameters of the hypothetical common delivery used for the calculations model are presented in the Supplementary Material (Figure S1).

\section{Results}

Between 2 June 2020 and 24 January 2021, 2452 of 3590 pregnant women agreed to participate in the study. Cumulative recruitment into the SCENARIO study is presented in $>$ Fig. 1. For 21 of the 2452 patients, the biological material was not suitable 


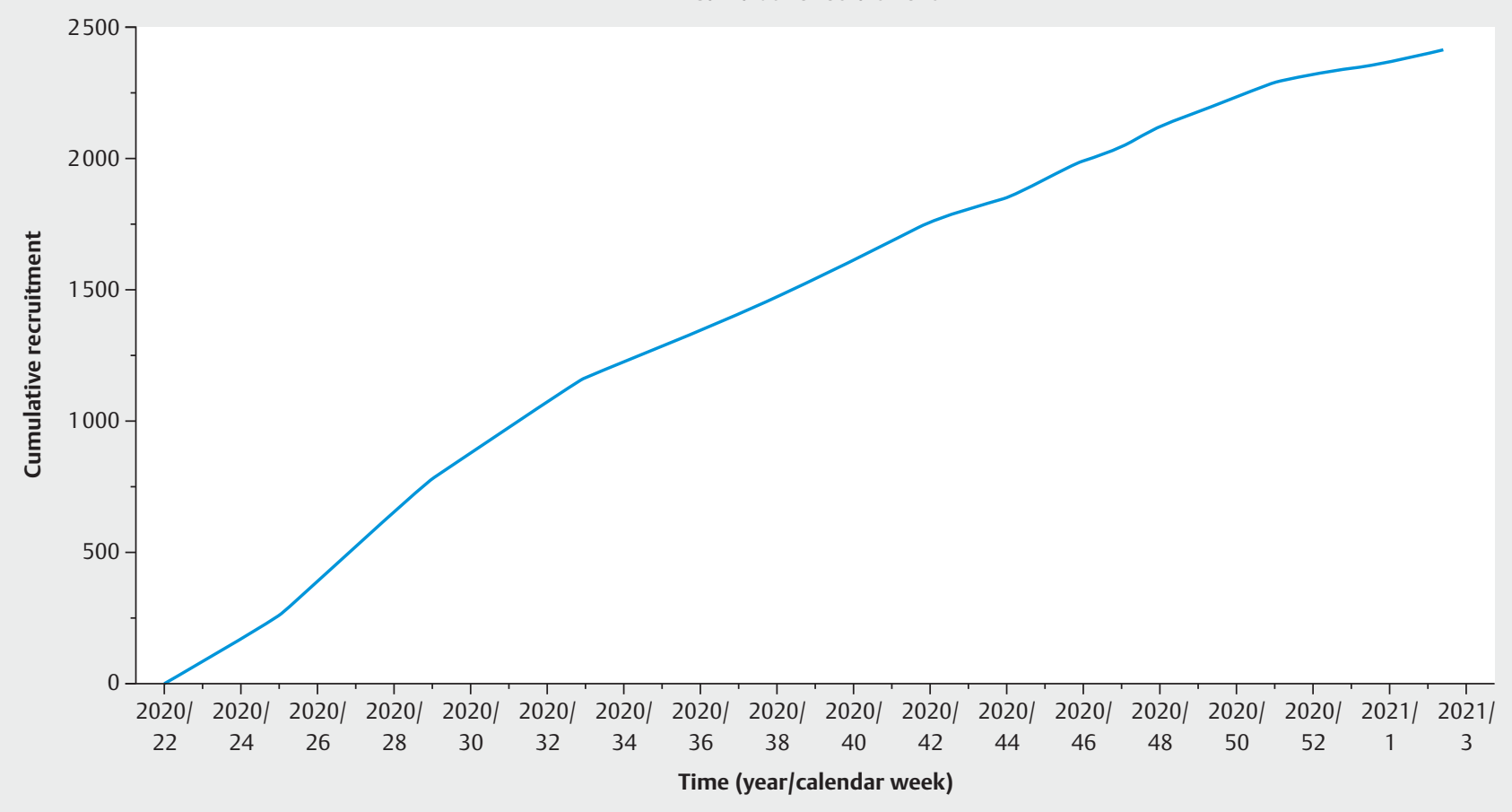

- Fig. 1 Recruitment into the SCENARIO study.

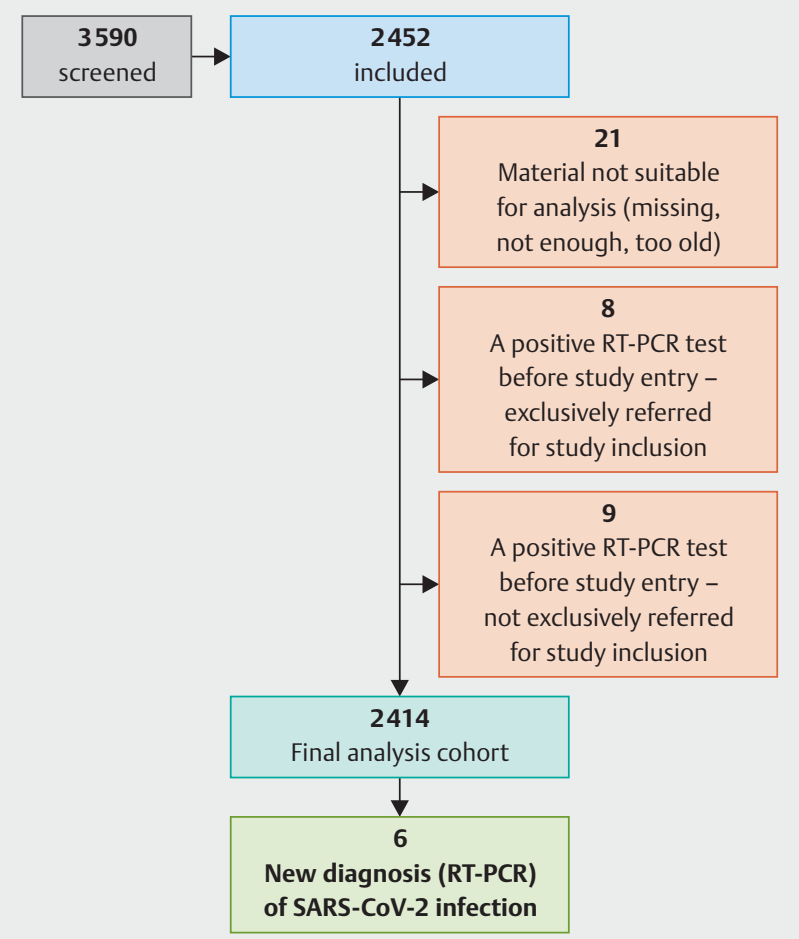

- Fig. 2 Flow chart of the screening, inclusion and testing process. for analysis (time between blood sampling and arrival in laboratory was too long for adequate assessment of antibodies or there was insufficient or missing material for analysis). A further $17 \mathrm{pa}$ tients with positive RT-PCR testing at study entry had to be excluded because of diagnosed SARS-CoV-2 infection prior to study entry, resulting in a final sample size of 2414 participants ( Fig. 2).

\section{General characteristics of the study population}

Descriptive statistics of the study population are shown in $>$ Table 1. The mean maternal age was 32.6 years, and the mean of gestational weeks at study entry was 33.8 (histogramm of gestational weeks at study entry is shown in Figure S2). Primigravidae formed the largest group (43.1\%). Obesity was found in $13.5 \%$ of women. Gestational diabetes occurred in $10.3 \%$ of this cohort, within the expected range (prevalence in Germany rises with age from $8 \%$ to $26 \%$ [39]).

\section{Prevalence and characteristics of RT-PCR positive cases}

Six women were found to be RT-PCR positive, implying a positive test rate of $0.25 \%(95 \% \mathrm{Cl}, 0.09-0.54 \%)$. Correction for sensitivity (95\%) and specificity (100\%) of the RT-PCR test yielded a prevalence of SARS-CoV-2 infection of $0.26 \%(95 \% \mathrm{Cl}, 0.10-0.57 \%)$.

The threshold cycle $\left(C_{t}\right)$ and symptom status of these six women are presented in $>$ Table 2 . $C_{t}$ values ranged from 16.1 to 36.6. Two cases had threshold cycles less than 30 . Two of the six women were symptomatic, and four were asymptomatic. 
- Table 1 Summary statistics for study population at study entry, showing mean with standard deviation (SD), median with minimum (min) and maximum (max) or frequency and percentage.

\begin{tabular}{|c|c|c|}
\hline Characteristic & & \\
\hline \multirow[t]{2}{*}{ Maternal age } & Mean (SD) & $32.6(4.7)$ \\
\hline & $\begin{array}{l}\text { Median } \\
(\min , \max )\end{array}$ & $32.7(16.8,48.4)$ \\
\hline \multirow{2}{*}{$\begin{array}{l}\text { Gestational week } \\
\text { at study entry }\end{array}$} & Mean (SD) & $33.8(7.3)$ \\
\hline & $\begin{array}{l}\text { Median } \\
\text { (min, max) }\end{array}$ & $36.0(2.1,42.0)$ \\
\hline \multirow[t]{4}{*}{ Gravidity } & 1 & $1040(43.1)$ \\
\hline & 2 & 793 (32.9) \\
\hline & 3 & $344(14.3)$ \\
\hline & $4+$ & $237(9.8)$ \\
\hline \multirow[t]{4}{*}{ Parity } & 0 & $1242(51.4)$ \\
\hline & 1 & $849(35.2)$ \\
\hline & 2 & $258(10.7)$ \\
\hline & $3+$ & $65(2.7)$ \\
\hline Obesity & Yes & $327(13.5)$ \\
\hline Anaemia & Yes & $81(3.4)$ \\
\hline Twin pregnancy & Yes & $78(3.2)$ \\
\hline Foetal growth restriction & Yes & $42(1.7)$ \\
\hline Pre-eclampsia & Yes & $33(1.4)$ \\
\hline Chronic hypertension & Yes & $43(1.8)$ \\
\hline Diabetes mellitus & Yes & $28(1.2)$ \\
\hline Gestational diabetes & Yes & $248(10.3)$ \\
\hline Gestational hypertension & Yes & $32(1.3)$ \\
\hline
\end{tabular}

- Fig. 3 shows SARS-CoV-2 positive cases in the SCENARIO study (6 newly diagnosed SARS-CoV-2 positive cases and 17 excluded SARS-CoV-2 positive cases with diagnosis before study entry) and SARS-CoV-2 7-day incidence values in the Franconian general population during the recruitment period (Data from RKI [40]).

\section{Estimation of risk of infection for healthcare workers}

The estimated infection risk of health care workers in delivery settings is shown in $>$ Table 3 . The average infectious pregnant woman in labour rarely transmits SARS-CoV-2 to medical staff in this model, even in a setting without room ventilation and masks (risk of infection $<1 \%$, scenario A). In cases where the pregnant woman is highly infectious, active room ventilation reduces the risk of transmission more efficiently than FFP2 masks (FFP is an abbreviation of filtering facepiece). The combination of both (scenario $E$ ) reduces the risk of infection for midwives and medical staff to less than $1 \%$. The additional presence of a partner with average infection, wearing a surgical mask, has no relevant additional effect on infection rates for midwives and obstetricians ( $\triangleright$ Table 3, scenario G). Infection risks in further settings with different ventilation and mask parameters are shown in $>$ Table $\mathbf{3}$, scenario B, C, D and F.
- Table 2 Threshold cycle $\left(C_{t}\right)$ and symptom status of newly diagnosed SARS-CoV-2-positive pregnant women.

\begin{tabular}{|l|l|l|}
\hline $\begin{array}{l}\text { Patient (Code in } \\
\text { SCENARIO study) }\end{array}$ & $\mathbf{C}_{\mathbf{t}}$ & Symptom status \\
\hline$\# 2550$ & 36.60 & Asymptomatic \\
\hline$\# 2549$ & 35.10 & Asymptomatic \\
\hline$\# 1679$ & 16.10 & Asymptomatic \\
\hline$\# 2239$ & 17.92 & Symptomatic \\
\hline$\# 2077$ & 22.92 & Symptomatic \\
\hline$\# 2204$ & 27.10 & Asymptomatic \\
\hline
\end{tabular}

\section{Discussion}

In this prospective cohort study, pregnant women in maternity units in Franconia, Germany were examined for acute SARS-CoV-2 infection between June 2020 and February 2021, corresponding to the time between the end of the first wave and the end of the second wave of the SARS-CoV-2 pandemic in Germany. This study is the first in Germany to carry out a systematic RT-PCR-screening on such a large group of pregnant women.

The prevalence of newly diagnosed SARS-CoV-2 infection was low in the cohort: only six out of 2414 pregnant women had their first positive SARS-CoV-2 RT-PCR. Two of the six had $C_{t}$ values above 30, indicating a low burden of viable SARS-CoV-2 [41].

In the same time frame as the SCENARIO study's time frame, $2.49 \%$ of the Franconian population were classified as SARS-CoV-2 positive [40], supporting international evidence that pregnant women do not have a higher risk of SARS-CoV-2 infection than non-pregnant individuals $[2,5,6]$.

The prevalence figures for SARS-CoV-2 in screened pregnant women vary in different publications, sometimes considerably $(<1-15 \%)$, which is largely due to the different prevalence in the general population (for example, New York City and London versus Thuringia in Germany) [28,30,42-46]. However, it is assumed that the "real" prevalence of infections is significantly higher, as up to $89 \%$ of infections are asymptomatic or mild [17, $28,29,47-52]$. Also in the SCENARIO cohort, four of the six positive cases where asymptomatic at study inclusion.

The high proportion of asymptomatic presentation at the time of testing among SARS-CoV-2-positive pregnant women highlights the importance of universally screening pregnant women admitted to maternity units during a pandemic. Detecting infected pregnant women is crucial to adjust medical management according to the elevated perinatal maternal and neonatal risk for these patients on the one hand and to reduce the risk of nosocomial transmission to health care workers and other pregnant women in the maternity units on the other hand.

Nevertheless, the absolute risk of infection for midwives and obstetricians attending the labour of a SARS-CoV-2-infected woman seems to be low ( $<1 \%)$, if adequate and continuous hygiene standards are guaranteed (such as room ventilation and wearing FFP2 masks). 


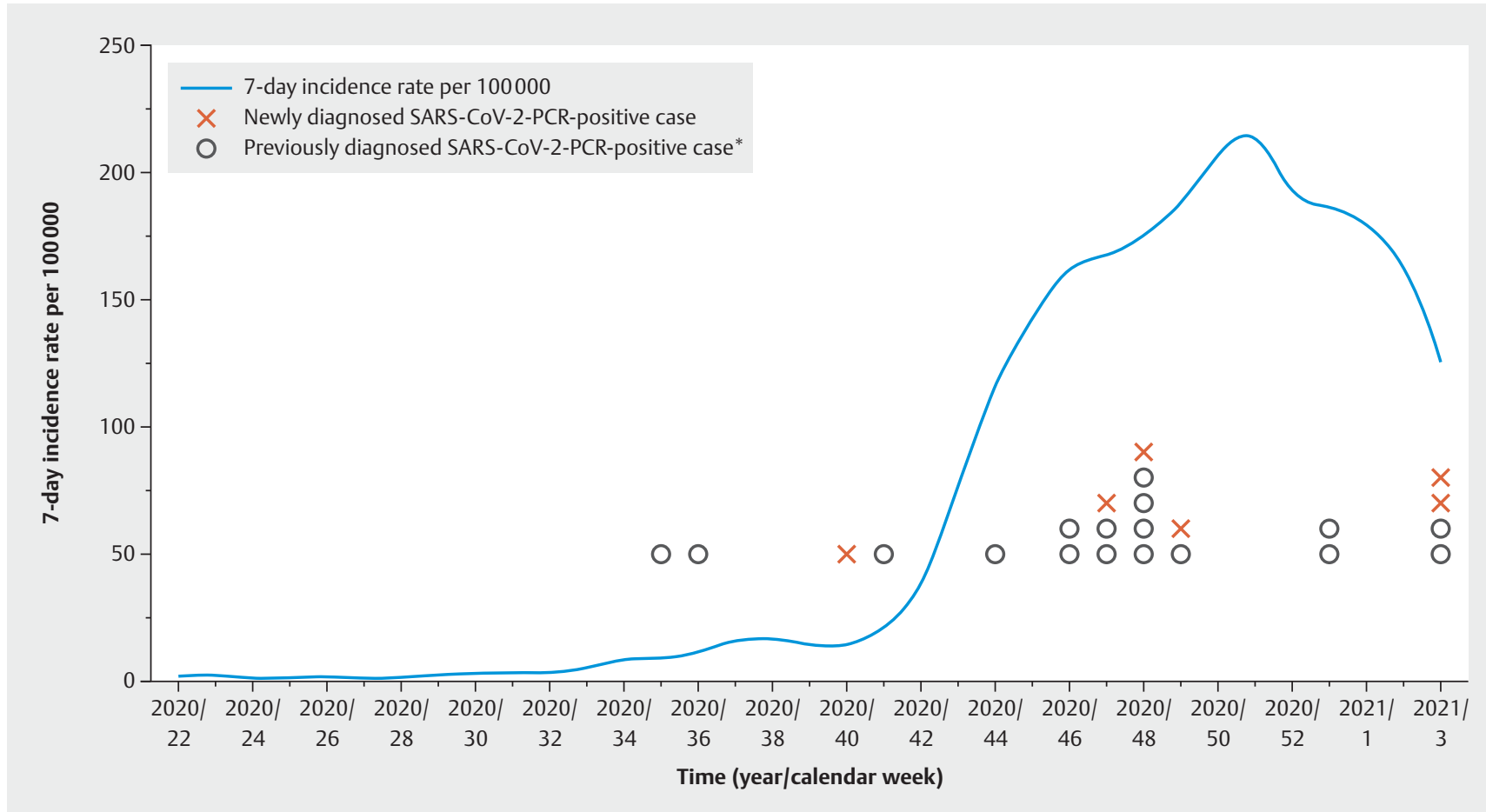

- Fig. 3 SARS-CoV-2 cases in the SCENARIO study and SARS-CoV-2 7-day incidence rate in the Franconian general population. * Previously diagnosed SARS-CoV-2-PCR-positive cases had a positive SARS-CoV-2 RT-PCR test before and at study entry. The figure shows time of positive RT-PCR test at study entry.

- Table 3 COVID-19 percentage infection risk of health care workers though aerosol transmission of SARS-CoV-2 during a normal labour in the delivery room.

\begin{tabular}{|c|c|c|c|c|c|c|c|}
\hline \multirow[t]{2}{*}{ Scenarios } & A & B & C & D & E & $\mathbf{F}$ & G \\
\hline & \multicolumn{7}{|c|}{$\begin{array}{l}\text { Mother is highly infectious } \\
\text { with a viral load of } 5 \times 10^{8} \text { RNA copies } / \mathrm{mL} \\
\text { (represents } \sim 25 \% \text { of people who tested positive for SARS-CoV-2) }\end{array}$} \\
\hline Midwife (percentage infection risk) & 30 & 3.6 & 2.2 & 6.8 & 0.7 & 0.3 & 0.3 \\
\hline \multirow[t]{2}{*}{ Obstetrician (percentage infection risk) } & 10 & 1.1 & 0.7 & 2.1 & 0.2 & 0.1 & 0.1 \\
\hline & \multicolumn{7}{|c|}{$\begin{array}{l}\text { Mother is averagely infectious } \\
\text { with a viral load of } 10^{7} \text { RNA copies } / \mathrm{mL} \\
\text { (represents the average viral load of people who tested positive for SARS-CoV-2) }\end{array}$} \\
\hline Midwife (percentage infection risk) & 0.7 & 0.1 & $\sim 0$ & 0.1 & $\sim 0$ & $\sim 0$ & $\sim 0$ \\
\hline Obstetrician (percentage infection risk) & 0.2 & 0 & $\sim 0$ & $\sim 0$ & $\sim 0$ & $\sim 0$ & $\sim 0$ \\
\hline \multicolumn{8}{|l|}{ Scenarios: } \\
\hline \multicolumn{8}{|l|}{ A: Without ventilation or masks } \\
\hline \multicolumn{8}{|l|}{ B: With active ventilation, without masks } \\
\hline \multicolumn{8}{|l|}{ C: With active ventilation and surgical masks } \\
\hline \multicolumn{8}{|l|}{ D: Without ventilation, with FFP2 masks } \\
\hline \multicolumn{8}{|l|}{ E: With active ventilation and FFP2 masks } \\
\hline \multicolumn{8}{|c|}{ F: E plus the mother wearing a surgical mask } \\
\hline G: F plus the partner present, being avera & y infec & wearin & I mask & & & & \\
\hline
\end{tabular}


Pregnancy and SARS-CoV-2 infection in Germany are also addressed by the COVID-19 Related Obstetric and Neonatal Outcome Study (CRONOS registry) [53]. Compared to the SCENARIO study, the CRONOS registry includes extensive documentation of the clinical parameters of SARS-CoV-2 positive pregnant women and their newborns. Due to the multicenter design through Germany plus Linz in Austria, larger case numbers can be obtained. Nevertheless, the CRONOS data are limited in that no conclusions can be drawn about the actual prevalence in pregnant women due to the study design [53]. In contrast, all pregnant women in the SCENARIO study were universally screened for SARS-CoV-2 infection. The screening allowed conclusions to be drawn about prevalence, specifically in the specified region of Franconia in Bavaria, Germany. Additionally, the presented data from SCENARIO supports the non-increased risk of infection of pregnant women compared to the general population as discussed in the updated recommendations on SARS-CoV-2/COVID-19 and pregnancy, childbirth and childbed [54] and previously presented in a period prevalence analysis of Jena in Thuringia, Germany [43]. Furthermore, the data presented support the recommendations [54] as they including testing of pregnant women on admission to the clinic and wearing of mouth and nose protection. Therefore, the data from the SCENARIO study are an important and scientifically relevant addition to the previously published data [53] and the current recommendations on SARS-CoV-2/COVID-19 in pregnancy [54].

A limitation of this first analysis of the SCENARIO study is the low number of pregnant women who tested positive for SARSCoV-2, which limits the information available on the effects of SARS-CoV-2 infection in pregnancy on the mother and child. Regarding the interpretation of infectivity, it has to be considered that $C_{t}$ values might be influenced by factors such as the quality of nasopharyngeal swab and the time of sampling during the course of infection [55]. The low numbers of pregnant women who tested positive for SARS-CoV-2 did not allow for further statistical analyses of risk factors, disease progression and other factors. These analyses can only be performed in larger studies. Therefore, the data collected within the SCENARIO study are made available for large registries and aggregated studies or cohorts to further investigate prevalence, risk factors or disease progression.

According to current information and listings from the RKI [56] and the German Register of Clinical Studies, the SCENARIO study is the largest study in Germany to examine the prevalence of SARS-CoV-2 in a cohort of pregnant women. Other strengths of this study include systematic screening in a large region and the possibility of regular follow-up examinations. This allows the evaluation of antibody courses and the determination of the time of a new infection during pregnancy.

\section{Conclusion}

To summarise, the prevalence of newly diagnosed SARS-CoV-2 infection during pregnancy in this first analysis of our study is low. As pregnant women are at higher risk of complications in case of SARS-CoV-2 infection, and transmission to other patients and health care workers has to be prevented, systematic screening in maternity units during pandemic situations is crucial to adjust hygiene and medical management. Nevertheless, the calculated infection risk during labour for medical health care workers in an adequately hygienic setting is low.

\section{Supplements}

Questionnaire: Self reporting questionnaire for COVID-19-related symptoms, secondary diseases and abnormalities during pregnancy.

Figure S1: Settings for the calculation of infection risk for medical staff in the delivery room.

The parameters presented in the Figure are estimated average times, speech volume, speaking/breathing ratio and respiration rate of the mother in a hypothetical normal labour of 11.6 hours in the delivery room. Estimated length of stay in the delivery room of partner, midwife and obstetrician is also shown for every stage of delivery.

Figure S2: Histogramm of gestational weeks at study entry.

\section{Acknowledgements}

We are extremely grateful to all the pregnant women in Franconia who took part in this study and gave blood during the pandemic. We are indebted to all the medical staff who were involved in the blood collection at the recruiting medical centres: University Hospital Erlangen, ANregiomed Klinikum Ansbach, Klinik Hallerwiese, REGIOMED Klinikum Coburg, St. Theresien-Krankenhaus Nürnberg gGmbH, Klinikum Aschaffenburg-Alzenau gGmbH, Klinikum Bayreuth GmbH, Klinikum Forchheim-Fränkische Schweiz and Klinikum Fürth.

The contribution of Rebecca Peuker to this publication was performed in partial fulfilment of the requirements for obtaining a doctoral medical degree. Parts of the work published here have been used for her doctoral thesis at the medical faculty of the Friedrich-Alexander-Universität Erlangen-Nürnberg.

Conflict of Interest

The authors declare that they have no conflict of interest.

\section{References}

[1] Wu Z, McGoogan JM. Asymptomatic and Pre-Symptomatic COVID-19 in China. Infect Dis Poverty 2020; 9: 72

[2] Wu Z, McGoogan JM. Characteristics of and Important Lessons From the Coronavirus Disease 2019 (COVID-19) Outbreak in China: Summary of a Report of 72314 Cases From the Chinese Center for Disease Control and Prevention. JAMA 2020; 323: 1239-1242

[3] Lu R, Zhao X, Li J et al. Genomic characterisation and epidemiology of 2019 novel coronavirus: implications for virus origins and receptor binding. Lancet 2020; 395: 565-574

[4] Stumpfe FM, Titzmann A, Schneider MO et al. SARS-CoV-2 Infection in Pregnancy - a Review of the Current Literature and Possible Impact on Maternal and Neonatal Outcome. Geburtshilfe Frauenheilkd 2020; 80: 380-390

[5] Knight M, Bunch K, Vousden N et al. Characteristics and outcomes of pregnant women admitted to hospital with confirmed SARS-CoV-2 infection in UK: national population based cohort study. BMJ 2020; 369: $\mathrm{m} 2107$ 
[6] Pettirosso E, Giles M, Cole S et al. COVID-19 and pregnancy: A review of clinical characteristics, obstetric outcomes and vertical transmission. Aust N ZJ Obstet Gynaecol 2020; 60: 640-659

[7] Ellington S, Strid P, Tong VT et al. Characteristics of Women of Reproductive Age with Laboratory-Confirmed SARS-CoV-2 Infection by Pregnancy Status - United States, January 22-June 7, 2020. MMWR Morb Mortal Wkly Rep 2020; 69: 769-775

[8] Zambrano LD, Ellington S, Strid P et al. Update: Characteristics of Symptomatic Women of Reproductive Age with Laboratory-Confirmed SARSCoV-2 Infection by Pregnancy Status - United States, January 22-October 3, 2020. MMWR Morb Mortal Wkly Rep 2020; 69: 1641-1647

[9] Capobianco G, Saderi L, Aliberti S et al. COVID-19 in pregnant women: A systematic review and meta-analysis. Eur J Obstet Gynecol Reprod Biol 2020; 252: 543-558

[10] Antoun L, Taweel NE, Ahmed I et al. Maternal COVID-19 infection, clinical characteristics, pregnancy, and neonatal outcome: A prospective cohort study. Eur J Obstet Gynecol Reprod Biol 2020; 252: 559-562

[11] Khalil A, Kalafat E, Benlioglu C et al. SARS-CoV-2 infection in pregnancy: A systematic review and meta-analysis of clinical features and pregnancy outcomes. EClinicalMedicine 2020; 25: 100446

[12] Diriba K, Awulachew E, Getu E. The effect of coronavirus infection (SARSCoV-2, MERS-CoV, and SARS-CoV) during pregnancy and the possibility of vertical maternal-fetal transmission: a systematic review and metaanalysis. Eur J Med Res 2020; 25: 39

[13] Prochaska E, Jang M, Burd I. COVID-19 in pregnancy: Placental and neonatal involvement. Am J Reprod Immunol 2020; 84: e13306

[14] Delahoy MJ, Whitaker M, O'Halloran A et al. Characteristics and Maternal and Birth Outcomes of Hospitalized Pregnant Women with LaboratoryConfirmed COVID-19 - COVID-NET, 13 States, March 1-August 22, 2020. MMWR Morb Mortal Wkly Rep 2020; 69: 1347-1354

[15] Jering KS, Claggett BL, Cunningham JW et al. Clinical Characteristics and Outcomes of Hospitalized Women Giving Birth With and Without COVID-19. JAMA Intern Med 2021; 181: 714-717

[16] Villar J, Ariff S, Gunier RB et al. Maternal and Neonatal Morbidity and Mortality Among Pregnant Women With and Without COVID-19 Infection: The INTERCOVID Multinational Cohort Study. JAMA Pediatr 2021; 175: 817-826

[17] Allotey J, Stallings E, Bonet M et al. Clinical manifestations, risk factors, and maternal and perinatal outcomes of coronavirus disease 2019 in pregnancy: living systematic review and meta-analysis. BMJ 2020; 370: m3320

[18] Patane L, Morotti D, Giunta MR et al. Vertical transmission of coronavirus disease 2019: severe acute respiratory syndrome coronavirus 2 RNA on the fetal side of the placenta in pregnancies with coronavirus disease 2019-positive mothers and neonates at birth. Am J Obstet Gynecol MFM 2020; 2: 100145

[19] Dong L, Tian J, He S et al. Possible Vertical Transmission of SARS-CoV-2 From an Infected Mother to Her Newborn. JAMA 2020; 323: 1846-1848

[20] Zeng L, Xiao T, Zhou W. Vertical Transmission of Severe Acute Respiratory Syndrome Coronavirus 2 From the Mother to the Infant-Reply. JAMA Pediatr 2020; 174: 1008-1009

[21] Zamaniyan M, Ebadi A, Aghajanpoor S et al. Preterm delivery, maternal death, and vertical transmission in a pregnant woman with COVID-19 infection. Prenat Diagn 2020; 40: 1759-1761

[22] Raschetti R, Vivanti AJ, Vauloup-Fellous C et al. Synthesis and systematic review of reported neonatal SARS-CoV-2 infections. Nat Commun 2020; 11: 5164

[23] Fenizia C, Biasin M, Cetin I et al. Analysis of SARS-CoV-2 vertical transmission during pregnancy. Nat Commun 2020; 11: 5128

[24] Woodworth KR, Olsen EO, Neelam V et al. Birth and Infant Outcomes Following Laboratory-Confirmed SARS-CoV-2 Infection in Pregnancy SET-NET, 16 Jurisdictions, March 29-October 14, 2020. MMWR Morb Mortal Wkly Rep 2020; 69: 1635-1640
[25] Walker KF, O’Donoghue K, Grace N et al. Maternal transmission of SARSCOV-2 to the neonate, and possible routes for such transmission: a systematic review and critical analysis. BJOG 2020; 127: 1324-1336

[26] Mand N, lannaccone A, Longardt AC et al.; CRONOS Network; CRONOSNetwork. Neonatal outcome following maternal infection with SARSCoV-2 in Germany: COVID-19-Related Obstetric and Neonatal Outcome Study (CRONOS). Arch Dis Child Fetal Neonatal Ed 2021. doi:10.1136/ archdischild-2021-322100

[27] Gale C, Quigley MA, Placzek A et al. Characteristics and outcomes of neonatal SARS-CoV-2 infection in the UK: a prospective national cohort study using active surveillance. Lancet Child Adolesc Health 2021; 5: 113-121

[28] Sutton D, Fuchs K, D'Alton M et al. Universal Screening for SARS-CoV-2 in Women Admitted for Delivery. N Engl J Med 2020; 382: 2163-2164

[29] Prabhu M, Cagino K, Matthews KC et al. Pregnancy and postpartum outcomes in a universally tested population for SARS-CoV-2 in New York City: a prospective cohort study. BJOG 2020; 127: 1548-1556

[30] Grossi E, Agnoli B, Baldini M et al. Universal Sars-Cov-2 Screening in Pregnant Women: Experience from the Italian Epidemic Outbreak. Acta Biomed 2021; 92 (S2): e2021001

[31] Diaz-Corvillon P, Monckeberg M, Barros A et al. Routine screening for SARS CoV-2 in unselected pregnant women at delivery. PLoS One 2020; 15: e0239887

[32] German Federal Statistical Office (Destatis). Kreisfreie Städte und Landkreise nach Fläche, Bevölkerung und Bevölkerungsdichte am 31.12.2020. 2021. Accessed May 01, 2021 at: https://www.destatis.de

[33] Bavarian State Office for Statistics (LfStat). Statistik der Geburten. 2021. Accessed May 01, 2021 at: https://www.statistikdaten.bayern.de/

[34] WHO. Laboratory testing for coronavirus disease (COVID-19) in suspected human cases. 2020. Accessed May 01, 2021 at: https://apps. who.int/iris/rest/bitstreams/1272454/retrieve

[35] Streeck H, Schulte B, Kummerer BM et al. Infection fatality rate of SARSCoV2 in a super-spreading event in Germany. Nat Commun 2020; 11 : 5829

[36] Rogan W], Gladen B. Estimating prevalence from the results of a screening test. Am J Epidemiol 1978; 107: 71-76

[37] Corman VM, Landt O, Kaiser M et al. Detection of 2019 novel coronavirus (2019-nCoV) by real-time RT-PCR. Euro Surveill 2020; 25: 2000045

[38] Lelieveld J, Helleis F, Borrmann S et al. Model Calculations of Aerosol Transmission and Infection Risk of COVID-19 in Indoor Environments. Int J Environ Res Public Health 2020; 17: 8114

[39] Melchior H, Kurch-Bek D, Mund M. The Prevalence of Gestational Diabetes. Dtsch Arztebl Int 2017; 114: 412-418

[40] Robert Koch Institute (RKI). COVID-19 Datenhub. 2021. Accessed May 01, 2021 at: https://npgeo-corona-npgeo-de.hub.arcgis.com/

[41] Young BE, Ong SWX, Ng LFP et al.; Singapore 2019 Novel Coronavirus Outbreak Research team. Viral Dynamics and Immune Correlates of Coronavirus Disease 2019 (COVID-19) Severity. Clin Infect Dis 2021; 73: e2932-e2942. doi:10.1093/cid/ciaa1280

[42] Khalil A, Hill R, Ladhani S et al. COVID-19 screening of health-care workers in a London maternity hospital. Lancet Infect Dis 2021; 21: 23-24

[43] Zollkau J, Baier M, Scherag A et al. [Period Prevalence of SARS-CoV-2 in an Unselected Sample of Pregnant Women in Jena, Thuringia]. Z Geburtshilfe Neonatol 2020; 224: 194-198

[44] Xu R, Pauley TA, Missfelder-Lobos $H$ et al. Samba II PCR testing for COVID-19 in pregnant women: a retrospective cohort study and literature review. BMC Pregnancy Childbirth 2021; 21: 212

[45] Saviron-Cornudella R, Villalba A, Esteban LM et al. Screening of severe acute respiratory syndrome coronavirus- 2 infection during labor and delivery using polymerase chain reaction and immunoglobulin testing. Life Sci 2021; 271: 119200 
[46] Piekarski P, Sateja M, Maciejewski T et al. No COVID-19 Cases Detected Between April and September 2020 After Screening All 838 Admissions to a Maternity Unit in Poland. Med Sci Monit 2021; 27: e929123

[47] Khalil A, Hill R, Ladhani S et al. Severe acute respiratory syndrome coronavirus 2 in pregnancy: symptomatic pregnant women are only the tip of the iceberg. Am J Obstet Gynecol 2020; 223: 296-297

[48] Longardt AC, Winkler VP, Pecks U. [SARS-CoV-2 and Perinatal Aspects]. Z Geburtshilfe Neonatol 2020; 224: 181-186

[49] Miller ES, Grobman WA, Sakowicz A et al. Clinical Implications of Universal Severe Acute Respiratory Syndrome Coronavirus 2 (SARS-CoV-2) Testing in Pregnancy. Obstet Gynecol 2020; 136: 232-234

[50] Massarotti C, Adriano M, Cagnacci A et al. Asymptomatic SARS-CoV-2 infections in pregnant patients in an Italian city during the complete lockdown. J Med Virol 2021; 93: 1758-1760

[51] Tanacan A, Erol SA, Turgay B et al. The rate of SARS-CoV-2 positivity in asymptomatic pregnant women admitted to hospital for delivery: Experience of a pandemic center in Turkey. Eur J Obstet Gynecol Reprod Biol 2020; 253: 31-34
[52] Maru S, Patil U, Carroll-Bennett R et al. Universal screening for SARSCoV-2 infection among pregnant women at Elmhurst Hospital Center, Queens, New York. PLoS One 2020; 15: e0238409

[53] Pecks U, Kuschel B, Mense L et al. Pregnancy and SARS-CoV-2 Infection in Germany-the CRONOS Registry. Dtsch Arztebl Int 2020; 117: 841842

[54] Zollkau J, Hagenbeck C, Hecher K et al. [Update on Recommendations for SARS-CoV-2/COVID-19 During Pregnancy, Birth and Childbed]. Z Geburtshilfe Neonatol 2020; 224: 217-222

[55] Ade C, Pum J, Abele I et al. Analysis of cycle threshold values in SARSCoV-2-PCR in a long-term study. J Clin Virol 2021; 138: 104791

[56] Robert Koch Institute (RKI). Antikörperstudien in der Allgemeinbevölkerung. 2020. Accessed May 01, 2021 at: https://www.rki.de/DE/Content/ InfAZ/N/Neuartiges_Coronavirus/AK-Studien/AKS_Allgemein.html 